\title{
UK fraud verdict prompts moves on ethics...
}

London. Attempts by the British scientific research establishment to prevent scientific fraud were given new urgency last week when the General Medical Council struck off the medical register a consultant, Malcolm Pearce, who had been found guilty of publishing two fraudulent papers in the British Journal of Obstetrics and Gynaecology.

The Medical Research Council (MRC) is drafting a comprehensive document on good research practice, to be released next year, that will cover the topics of scientific fraud and 'whistleblowing'.

Martin Kemp, head of research policy development at MRC, says that "there is scope for laboratories to do more internal screening". The MRC is planning a clear sanctions package, coupled with rigid procedures for inquiring into scientific fraud designed to safeguard whistleblowers.

Meanwhile, the Royal College of Physicians (RCP) is expected to announce this week plans to set up an independent body to regulate medical research. According to its registrar, David London, the college would like to see the creation of a body able to commission inquiries and receive complaints, similar to those that already operate in Scandinavia. "Where there is crime, one needs a degree of policing," says London.

Pearce, a consultant obstetrician at St George's Hospital in London, was found guilty of 12 charges of professional misconduct - including two of scientific fraud over two papers published in August 1994.

In the first paper, co-authored with his head of department, Geoffrey Chamberlain, who resigned last week as president of the Royal College of Obstetrics and Gynaecology, Pearce claimed that he had carried out the world's first successful transplantation of an ectopic pregnancy.

The second paper contained an entirely fabricated report on 191 women suffering recurrent miscarriage. When questioned, Pearce later claimed none of the records of those included in this study could be found.

Issuing its verdict, the GMC, which regulates medical practice in the United Kingdom, condemned Pearce's "deliberate inclusion of false or misleading data in medical research" as dishonest and intolerable. The council described as "incalculable" the consequences for public confidence in the integrity of research.

In an effort to restore public confidence, the GMC emphasized the need to devise and operate effective safeguards, especially in the area of 'gift authorship' - the practice whereby senior academics add their names to research papers with which they have had little direct involvement. The council suggests that "all individuals named in a research paper must have made an intellectual contribution and be able to verify the raw data".
Stephen Lock, a former editor of the British Medical Journal who is an expert on the study of scientific fraud, describes the Pearce case as "a tragedy waiting to happen". He was impressed, however, by the swift and efficient manner in which the case - which lasted only eight months from beginning to end - was handled.

Lock, who advises the RCP on dealing with fraud cases, admits that medical research will inevitably produce a small percentage of "bad apples". But he adds that "peer review cannot - and can't be expected to - detect these", especially as "the whistleblower usually suffers more than the miscreant". He also supports calls for gift authorship to cease, comparing the practice to "saying that you helped Shakespeare write Hamlet because you lent him a pencil".

\section{... as US reviewer resigns over slur}

San Diego. A New York epidemiologist has resigned from a grant-reviewing committee of the US National Institutes of Health (NIH) over the treatment of a grant application from a research team at the University of Alabama at Birmingham, which was last month found guilty of stealing a key idea used in the application from a former research student.

Karla H. Damus of the Albert Einstein College of Medicine has resigned from the maternal and child health research committee of the National Institute of Child Health and Human Development, on which she had served for more than three years. Her resignation stems from her participation in the 1992 review of an application to renew a $\$ \mathbf{4}$.8-million grant from the Alabama team, which has been studying congenital cytomegalovirus (CMV) infections in newborn children.

Last month, the team was found guilty of using research results stolen from another scientist improperly to obtain federal grants (see Nature 375, 270; 1995). Details about the review process emerged during the federal lawsuit, in which Pamela A. Berge, an epidemiologist, had sued Robert F. Pass - head of paediatric infectious diseases at the university, and the principal investigator for a five-year grant seeking a vaccine against $\mathrm{CMV}$ and three Alabama colleagues for stealing results obtained while she was completing a thesis and for using them to win grants improperly from the institute.

A federal judge in Baltimore, Maryland, issued a \$1.9-million judgement against the university and the four researchers. Damus - who acknowledges having met Berge previously - claims that a spurious allegation that she had a conflict of interest was used by the Alabama team in 1992 to get its application re-reviewed after the review committee had not given it a sufficiently high rating to receive funding.

In March 1992, two days after the committee's decision, Pass wrote to institute officials claiming that Berge had influenced the review either through Damus or another review committee member. The institute subsequently convened a second committee of different reviewers, but that committee also gave the application an unfundable rating.

A third review by yet another committee finally gave the Alabama application a sufficiently high rating for it to be funded in May 1993. Institute officials say that the committee was unaware of the earlier decisions. But Damus claims that the successive reviews raise questions about the institute's policies for ensuring grants are evaluated on the basis of quality alone, and also for protecting reviewers who might be inappropriately criticized by grant applicants.

Damus claims that in 1992 she was unaware of Berge's dispute with the Alabama team, and says she did not learn about the conflict allegation - or the other two reviews of the grant - until one of Berge's attorneys contacted her last autumn. "I am furious over this," says Damus. "It is unconscionable that no-one at the institute would pick up the phone and call about such a serious allegation. I cannot be a reviewer until they set policies and guidelines to protect reviewers."

Charlotte Catz, the institute's project officer on the Alabama grant, acknowledged that three successive reviews were "unusual" and had never previously occurred in her 18-year tenure. She describes Damus as "an excellent reviewer", adding that it is regrettable that she was upset.

Although the institute never investigated Pass's conflict of interest allegations, Catz says that the additional reviews were "the most efficient way" of handling the matter. But Damus describes the institute's actions as a way of "covering up" a "really effective old boys' network" for reviewing and funding grants.

Pass has been unavailable for comment since the lawsuit, believed to be the first case in which a jury has ruled that scientists used research results stolen from another scientist to obtain federal grants. Despite last month's jury verdict, attorneys for Alabama and the researchers deny any impropriety, and are seeking to have the verdict set aside.
Rex Dalton 